\title{
A world of learning
}

The small publishing house Eichborn regrets that "whereas the Bible is sold off at any supermarket, Alexander von Humboldt's counter-theories to the holy writings are hard to find even in the largest of book shops". In the hope of correcting this, Eichborn is republishing three of the explorer-scientist's most important works.

Von Humboldt, born in 1769, remains one of Germany's most important intellectual figures. Deeply committed to Enlightenment principles, he was a collector of knowledge. He travelled extensively, learning the language of each country he visited. He was an internationalist, and persuaded Prussia's King Friedrich Wilhelm IV to inaugurate, in 1842, the Order Pour le mérite für Wissenschaften und Künste, the first such civilian society in war-torn Europe to recognize individual academic achievement across borders.

to place nutrient cycling in a mechanistic rather than a budgetary framework. The concept of the limitation of nutrients was central, defined as "occurring when the addition of an essential element increases the growth of individual organisms or populations, or increases the rate of a biological process" (F.S. Chapin etal. Am. Nat. 127,48-58; 1986). Nutrient limitation had long been known to foresters and agronomists as a spatially variable property but was usually treated as a static site characteristic. Following the publication of the nutrient-retention hypothesis by Vitousek and William Reiners (BioScience 25, 376-381; 1975), nutrient availability was viewed as an emergent property of an ecosystem, a dynamic property controlled by biological, hydrological and geological interactions.

I vividly remember Vitousek stating in a (probably beer-fuelled) conversation about research focus and scientific success that his focus was on "understanding nutrient limitation during succession". His work began by understanding the interactive controls over nutrient limitation after forest disturbance. In Nutrient Cycling and Limitation, Vitousek explores this theme on a grand canvas, basing it on his own work and that of a small army of students and collaborators.

The island of Hawaii is formed from lava flows of diverse and known ages spanning many millions of years. Ecosystems have developed on soils formed from these lava, drawing from a relatively common palette of species but under vastly different conditions of nutrient limitation, depending on the age of the soils. Vitousek reports on several decades of research using age gradients

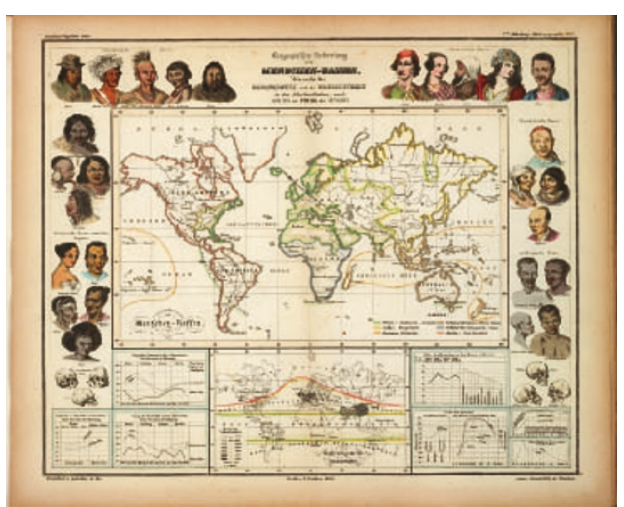

His massive tome Kosmos was an attempt to synthesize all the knowledge of the physical world, from thousands of different sources, including his own scientific travels. It was illustrated with maps like the one shown here, describing not only geography but also geology, biology and anthropology. Kosmos was a thirty-year labour of love, and von Humboldt was reportedly still adding to it on his dying day, aged 89. The work was a best seller in the nineteenth century, and was translated into many languages. But it faded from view in the twentieth century, and few Germans today have read the original words.

The publication of Kosmos marks the 200th anniversary of Humboldt's return from his five-year exploration of the Americas.

The two companion volumes are Ansichten der Natur (Views of Nature) and the sumptuously illustrated Ansichten der Kordilleren und Monumente der eingeborenen Völker Amerikas (Views of the Cordilleras and Monuments of the indigenous American Peoples), which has, in fact, never previously been published in German.

www.eichborn.de (along with climatic gradients and manipulation and natural disturbance within the geological template) aimed at understanding how nutrient limitation has evolved as the lava soils of Hawaii have aged over the past 5 million years or so.

He expands the concepts of nutrient cycling, inputs and losses on the ecosystem disturbance and recovery time scale (from 10 to 1,000 years) to geological time. Pro-

ratios reflecting these inputs over the ages.

While Nutrient Cycling and Limitation builds a strong bridge to the geological view of biogeochemistry, and to geological time scales, it also extends the biological paradigm. In geochemistry, organisms often appear as essentially passive transducers of physical forces into chemical dynamics. In this view, athough rates might differ in the presence or absence of organisms, the geophysical environment is viewed as shaping the system.

Vitousek's view of nature is richer by far. He shows how the biogeochemical characteristics of organisms can alter the trajectory of geochemical development, on multiple time scales. He views these organismal characteristics as being shaped by the organisms' deep evolutionary history. When organisms migrate to or invade Hawaii, the conflict between their evolutionary history and that of the island can create new biogeochemical conditions and complex responses. This leads to a contingent rather than an environmentally deterministic view of ecological dynamics, and is

cesses that on ecosystem time scales are either too slow to matter, or too episodic, come to dominate on geological time scales. Expanding the time scale expands the spatial scale as well: the parsimonious explanation for some aspects of Hawaiian geochemistry turns out to be the transport of nutrient-containing dust across the Pacific, a process that occurs at low instantaneous rates and during climatic episodes separated in geological time, but that is essential to budgets over millions of years. Today's Hawaiian ecosystem dynamics, though, are controlled partly by nutrient budgets and an important counterpart to the simpler views often espoused in biogeography.

This short review does not do justice to the range of topics addressed in Nutrient Cycling and Limitation, nor does it convey the depth of theoretical perspective couched in reams of hard-won experimental and observational data. This book will reward reading and rereading, and is an excellent introduction to biogeochemical ecology for those coming from other fields of science.

David Schimel is at the National Center for

Atmospheric Research, Boulder,

Colorado 80305, USA. 